\title{
O trabalho no campo da educação: o Fórum-Cosate como estratégia de resistência à máquina neoliberal
}

\author{
Maria Elizabeth Barros de Barros ${ }^{1}$ e Cristiane Bremenkamp Cruz ${ }^{2}$ \\ Universidade Federal do Espírito Santo (Vitória, ES, Brasil)
}

\begin{abstract}
O artigo introduz uma experiência de pesquisa-intervenção realizada na região metropolitana de Vitória, Espírito Santo, mais especificamente no município de Serra visando ao fortalecimento de práticas no contexto escolar que possam fazer frente à racionalidade neoliberal que toma a educação como bem privado de valor econômico. Apresenta a constituição de um fórum de trabalhadores da educação cujo objetivo é construir estratégias que possam desafiar o processo de adoecimento em curso nas escolas, decorrente da racionalidade econômica vigente no referido município. Aponta como direção ética a indissociabilidade entre clínica e política e aposta na criação de táticas coletivas de enfrentamento ao adoecimento nas unidades escolares da rede.
\end{abstract}

Palavras-chave: Educação, Trabalho, Cogestão.

Labor in the field of education: fórum-cosate as a strategy of resistance against the neoliberal machine

This article presents the experience of a research-intervention carried out in the municipality of Serra, metropolitan region of Vitória, Espírito Santo, aiming to strengthen practices in the school context that can face the neoliberal rationality that considers education as private goods of economic value. It describes the constitution of a forum for education workers to develop strategies that could challenge the sickness process underway in schools, due to the economics-guided thinking in that municipality. Its ethical direction, the inseparability between clinic and politics as well as the investment in the creation of collective tactics to fight sickness in the school units of the city are highlighted.

Keywords: Education, Labor, Co-management.

\section{O contexto da pesquisa}

$\mathrm{N}$ os últimos 14 anos, os pesquisadores de um grupo de pesquisa de uma universidade pública do sudeste brasileiro vinculado ao Conselho Nacional de Desenvolvimento Científico e Tecnológico (CNPq) - o Núcleo de Estudos em Subjetividade e Políticas (Nepesp) - trabalham visando à implantação de Comissões de Saúde do Trabalhador da Educação (Cosate) no município de Serra, Espírito Santo (ES), Brasil. Trata-se do mais populoso do estado, com 517.510 habitantes conforme estimativa de 2019 do Instituto Brasileiro de Geografia e Estatística (IBGE). Está localizado na Microrregião de Vitória (capital do Espírito Santo), na Mesorregião Central Espírito-Santense e pertence à Região Metropolitana de Vitória, situando-se a 27 quilômetros ao norte da capital do estado.

A pesquisa, intitulada Programa de Formação e Investigação em Saúde e Trabalho (PFIST), visa efetivar processos formativos no campo da educação com o objetivo de implantar Comissões de Saúde do Trabalhador (Cosate) nas escolas. A proposta das comissões tem como direção metodológica as Comunidades Cientificas Ampliadas (CCA), inspiradas no Movimento Operário Italiano (MOI) da década de 1970 (Oddone, Marri \& Gloria, 1986), para o exercício coletivo de análise da atividade docente nesse município. Consideramos que a estratégia das comissões por local de trabalho é um potente instrumento para intervir nas condições adversas de trabalho nas escolas.

https://orcid.org/0000-0003-1123-4374

2 https://orcid.org/0000-0003-0854-7687 
A rede escolar do município de Serra, ES atualmente conta com 139 unidades de ensino, entre Centros Municipais de Educação Infantil (CMEIs) e Escolas com Ensino Fundamental (EMEFs), que atendem a 21.500 crianças de 0 a 6 anos, matriculadas nos Centros Municipais de Educação Infantil, e 43.082 alunos matriculados no ensino fundamental, sendo o número total de alunos 67.300. A rede é composta, ainda, por 6.093 servidores da Secretaria de Educação, incluindo 5.695 professores e 464 pedagogos (Prefeitura Municipal de Serra, 2020a).

A pesquisa-intervenção foi desenvolvida a partir de uma preocupação frente aos dados produzidos pelo grupo de pesquisa, que realizou um inquérito de saúde no ano de $2014^{3}$, cujo resultado indicava o aumento do índice de adoecimento entre os educadores nos últimos anos. Visávamos, principalmente, conhecer como os professores se percebiam, interpretavam e nomeavam sua condição de saúde/adoecimento. Na resposta ao inquérito, 65,7\% dos educadores mencionavam o ritmo intenso do trabalho, o tempo insuficiente para o descanso, o número de alunos nas salas de aula e os modos de gestão nas escolas como principais determinantes de adoecimento, que ganhava números preocupantes. Segundo educadores que participaram do inquérito, um dos motivos recorrentes na produção de tal quadro era o isolamento no desenvolvimento do fazer educacional e os modos de gestão verticalizados e autoritários atualizados nas escolas. A utilização do inquérito de saúde foi uma estratégia-dispositivo cujo objetivo foi o de produzir formas de dialogar com os educadores e gerentes da rede a fim de rearranjar as potências e sensibilidades ao tema saúde e trabalho na educação. Objetivávamos puxar linhas, espraiar a conversa e alinhavar interesses para compor um cenário dialógico que abrigasse a construção e sustentação de um fórum para debater as condições de saúde/adoecimento.

Os dados detalhados desse inquérito de saúde foram apresentados à Secretaria de Educação que, então, nos relatou uma preocupação com o alto índice de absenteísmo na rede. Assim, abríamos um campo problemático com um atravessamento político-institucional complexo que necessitava intervenção. Com base no inquérito e na conversa com a Secretaria de Educação da Serra, demos início a um processo de convocação para participação em um fórum. Esta convocação foi feita a partir de uma lista de e-mails de todos os educadores da rede, disponibilizada pela Secretaria de Educação. O convite foi feito, ainda, para representantes do Centro de Formação de professores da Serra, ES, para o Sindicato dos Trabalhadores em Educação Pública do ES, para o Centro de Referência em Saúde do Trabalhador/ES, para o Ministério Público estadual, bem como para instâncias de controle social, como o Conselho Municipal de Educação e a universidade pública, representada pelo nosso grupo de pesquisa. Os encontros eram abertos para outros representantes da sociedade civil que se interessassem em participar do processo. A reunião do fórum tinha periodicidade quinzenal ou mensal, dependendo da disponibilidade dos membros participantes, e cada encontro tinha a duração de 4 horas, em média.

De forma esquemática, podemos afirmar, então, que a pesquisa seguiu as etapas seguintes (às vezes de modo concomitante): 1) Levantamento de informações feito por meio de um Inquérito de Saúde; 2) Convocação para participação no fórum; 3) Concomitantemente à realização do fórum (com ação quinzenal/mensal) entre os anos de 2012 e 2014, houve decisão colegiada e escolha de duas escolas para fazer um projeto-piloto para implantação de Comissões de Saúde na rede estadual de educação; 4) Formulação, aprovação e sancionamento da Lei municipal no 4.513, de 05 de maio de 2016, que criou as Comissões de Saúde do Trabalhador da Educação (Cosate) do serviço público do município de Serra, ES; 5) Surgimento de Comunidades Ampliadas de Pesquisa, constituídas por pesquisadores da Universidade Federal do Espírito Santo (UFES) e trabalhadores de Serra; 6) Constituição de um Núcleo de Saúde na Secretaria de Educação do município; 7) Formação para

3 Sobre o inquérito de saúde, ver Luciano, Barros \& Raizem (2016). 
diretores, professores e gestores - o que aconteceu em diversos momentos deste período, desde 2012 até o segundo semestre de 2019, entre outras ações no decurso destes anos.

A pesquisa já se desdobrou em várias publicações ${ }^{4}$, sendo que em cada uma focamos uma dimensão dela. Neste artigo, nosso foco é apresentar uma das estratégias utilizadas na pesquisa: o Fórum-Cosate, que funcionou como catalisador de ações e sensibilidades e atravessou a realização das outras ações da pesquisa entre 2012 e 2019. A experiência com o fórum objetivava fortalecer práticas no contexto escolar que pudessem fazer frente a uma racionalidade neoliberal, que toma a educação como bem privado e de valor econômico, conforme nos indicavam os dados do inquérito de saúde. A direção ético-política da pesquisa foi efetivada a partir de uma direção metodológica das clínicas do trabalho ${ }^{5}$, de forma a incitar a criação de táticas de resistência e enfrentamento coletivo.

O processo foi disparado em agosto de 2012 com uma reunião intersetorial, proposta pelo nosso grupo de pesquisa, com o objetivo de discutir a viabilidade da implantação de Cosates em Serra, ES, já que tentativas anteriores foram desmobilizadas pelo Executivo municipal. Entendíamos que construir um processo de implementação de política pública de modo participativo é importante e legítimo. Desse modo, seria possível que trabalhadores da educação, conhecedores das dores e prazeres do seu fazer, fossem capazes de produzir, no diálogo com técnicos de segurança do trabalho ou da perícia, fonoaudiólogos, entre outros profissionais, novos conhecimentos acerca dos riscos no trabalho, além de terem maior visibilidade aos enfrentamentos e às resistências efetivadas no cotidiano municipal.

Em outubro de 2012, o primeiro movimento do Fórum foi analisar a Lei estadual no 5.627 de 17 de março de $1997^{6}$, que normatiza e institui as Comissões de Saúde por local de trabalho para os trabalhadores da saúde. A referida lei foi analisada e discutida no fórum de forma a adaptá-la para a realidade dos trabalhadores da educação de Serra, ES. Em setembro de 2013, o Fórum-Cosate teve assento na mesa de negociação sobre o Plano Nacional de Educação do Movimento Capixaba. Em junho de 2014, o Fórum-Cosate teve um de seus componentes como representante oficial na Conferência Estadual de Saúde do Trabalhador, garantindo a inclusão de um artigo sobre Saúde e Cosates nas escolas no documento consolidado para a etapa nacional. Essas reuniões transformaram-se num espaço coletivo permanente, importante ferramenta da pesquisa, tomado como uma coprodução da autonomia, uma forma de cogerir processos e abertura à polissemia das participações.

Ao serem repensadas as particularidades do campo educacional do referido município, o Fórum-Cosate problematizaria os efeitos da organização do trabalho para a qualidade do ensino e para a saúde dos trabalhadores, efeitos qualitativos advindos das lógicas de gestão e de participação decisória em vigor. Também pautaria uma agenda para a saúde do trabalhador da educação no projeto político-pedagógico das escolas da rede municipal do referido município.

\section{A axiomática do capitalismo neoliberal e o trabalho em educação}

Como já indicado, este texto parte de um cenário que expressa o modo como a gestão neoliberal da educação tem sido atualizada na rede municipal de educação da Serra, ES. A pesquisa nasce,

4 Um desses artigos está publicado no volume 22, número 1 da revista Cadernos de Psicologia Social e do Trabalho, com o título "A saúde do trabalhador da educação: a experiência da constituição de Cosates como dispositivo de intervenção numa rede municipal de ensino" (Barros, Muniz \& Brito, 2019).

5 Quando falamos de "clínica do trabalho", estamos nos referindo a um conjunto de abordagens voltadas para o estudo da relação entre trabalho e subjetividade. Tais abordagens têm como foco a situação concreta na qual os trabalhos são desenvolvidos, destacando-se os processos criadores e construtivos dos viventes e, em especial, o sujeito humano, na sua capacidade de mobilização, de ação e de resistência face ao real da atividade.

6 A Lei estadual no 5.627/98 de autoria da deputada estadual do ES Brice Bragato, cria a Comissão de Saúde do Trabalhador (Cosat) do serviço público do ES e o Conselho das Comissões de Saúde do Trabalhador (Concosat). 
portanto, de inquietações que emergem no cenário da educação pública desse município, que estava ao sabor das políticas do governo local. Mais especificamente, de uma governamentalidade ${ }^{7}$ neoliberal que se amplia e se fortalece na rede de ensino a cada mudança de gestão municipal. Tais mudanças são marcadas por políticas pautadas num discurso da austeridade, que fomentam competitividade, individualidade, intimismo, isolamento, privatização da vida, excesso de tarefas e perda do sentido de outras temporalidades menos aceleradas.

Desarticulam-se os coletivos de trabalho, sob o pretexto, muitas vezes, de qualificar cada vez mais o serviço público. São impostas políticas de desmonte, de precarização das relações trabalhistas, de redução de espaços de diálogo e de planejamento coletivo, de escassez de recursos financeiros; políticas estas que reduzem os processos de formação à capacitação técnica, dirigida para a fabricação dos diretores de escolas que atuem mais como gerentes administrativos do que como educadores.

Frente a esse quadro, urge indagar os modos de gerenciamento da educação no município que vêm exercendo um ataque ao ensino público, tentando desmontá-lo. O que acompanhamos hoje na cidade da Serra é a hegemonia de práticas de educação pautadas por essa racionalidade, expressas nas escolas da rede por um modelo que toma a educação como bem privado de valor econômico. Laval $(2004$, p. 3) corrobora essa ideia quando afirma que o "homem flexível e o trabalhador autônomo constituem, assim, as referências do novo ideal pedagógico".

Percebe-se de forma geral, no sistema educacional do Brasil, uma ampliação cada vez maior de lógicas administrativas e estatísticas, assim como o surgimento de técnicos ocupando postos importantes de trabalho, mesmo que não tenham um percurso no campo da educação. São estes que tendem a dar a última palavra sobre as políticas educacionais em cada escola e, também, no âmbito das redes de ensino, sob o pretexto de mudanças necessárias. Nessa direção, tensões políticas que impliquem conflito, controvérsias, debates de valores e ideias são esvaziadas. O gerenciamento da escola passa a ser voltado, então, para a escola "útil" e "prática", o que produz uma mudança importante no ofício do professor, uma vez que este deve passar a orientar seu trabalho no modo de pensar empresarial e se parecer com o "homem da organização".

Nesta direção, na rede educacional da Serra, ES, vários convênios com empresas privadas têm sido feitos para financiar programas que passam a fazer parte dos currículos escolares como, por exemplo, o Programa Educação em Valores Humanos, lançado em 2017 com apoio da empresa ArcelorMittal Tubarão. Esta empresa tornou-se a principal parceira na implementação do programa, que propunha, entre outras ações, a realização de aulas de honestidade e respeito, apresentando propostas pedagógicas com foco na "formação do caráter do indivíduo" de modo politicamente descontextualizado e individualizado (Prefeitura Municipal de Serra, 2020b). Além disso, em 2017, a Confederação Nacional dos Trabalhadores em Educação (CNTE) lançou uma moção de repúdio na ocasião da aprovação da Lei municipal no 4.602, de 23 de janeiro de 2017, que retirava garantias e direitos dos trabalhadores da educação, tais como quinquênio, decênio e progressão para os trabalhadores que ingressassem na rede municipal de Serra, ES a partir de janeiro de 2017.

7 Aqui o conceito de governamentalidade é entendido como "o conjunto constituído pelas instituições, procedimentos, análises e reflexões, os cálculos e as táticas que permitem exercer essa forma bem específica, ainda que complexa, de poder que tem por alvo principal a população, ... uma tendência, a linha de força que, em todo o Ocidente, não cessou de conduzir, e desde muito tempo, à permanência desse tipo de poder que podemos chamar de 'governo' sobre todos os outros: soberania, disciplina, e que, por uma parte, levou ao desenvolvimento de toda uma série de aparelhos específicos de governo, ao desenvolvimento de toda uma série de saberes" (Foucault, 2008, p. 111-112). 
Todas estas ações implementadas nos últimos anos, aliadas à destituição da força dos coletivos de trabalhadores da rede de ensino, vêm fragilizando as relações dos professores e das professoras com seus pares, com seus alunos e alunas e com o seu trabalho, levando eventualmente ao adoecimento. Os profissionais que atuam na educação se veem constrangidos em seu poder de agir ${ }^{8}$, em sua potência de invenção e criação.

As demandas que chegam à Perícia Médica - parte da Divisão de Medicina e Segurança do Trabalho/Serra, ES - são, geralmente, individualizadas, colocando nos trabalhadores e trabalhadoras a responsabilidade sobre as suas ações, sobre a sua saúde e, consequentemente, sobre a superação de seus problemas, desarticulando-os das maneiras como o trabalho se desenvolve nas escolas. Assim, as políticas de governamentalidade neoliberal geram efeitos na produção de saúde e doença desses profissionais a partir de abordagens que naturalizam o adoecimento, tomando-o como uma questão individual.

Neste sentido, um primeiro desafio que se colocou para a pesquisa foi afirmar uma clínica do trabalho crítico-política que ouse enfrentar as engrenagens governamentais em curso e incitar a criação de táticas de resistência e enfrentamento coletivo. A resistência que aqui se ratifica é da ordem da estratégia e da luta, imanente às relações de poder (Foucault, 2008), entendida como ato de criação, uma vez que cria modos de ser, de existir e de agir no campo da educação. "O ato de resistência não é obra de arte, mas faz parte dela. A obra de arte não é ato de resistência, mas de certa maneira ela o é" (Deleuze, 1987, p. 22). Nessa direção, a pesquisa foi se forjando como uma clínica do trabalho que se faz política, uma vez que coloca em análise a vida em sua dimensão processual, coletiva e histórica. Essa clínica não coloca a dicotomia individual versus o coletivo ou psicológico versus o social, mas afirma a indissociabilidade entre clínica e política.

Com essa direção de análise, apostamos numa clínica crítico-política, que se faz e se (re)faz cotidianamente pelo combate à produção das políticas de individualização e de "empresariamento" da vida, cujas práticas e intervenções incidem sobre o indivíduo isolado em seus processos de adoecimento. De outro modo, o diálogo num fórum perseguiria uma luta pela implementação de uma política de coletivização que sustentasse práticas e intervenções a partir de um plano "comum".

O que estamos afirmando, portanto, é que os efeitos dessas políticas, que foram explicitados no inquérito realizado junto aos docentes, se materializam no corpo dos trabalhadores e trabalhadoras, que, muitas vezes, sucumbem às produções engendradas pela máquina capitalista. A questão clínica do trabalho que adotamos posiciona-se no limiar entre as produções forjadas por essa máquina e a produção de resistência, que pode provocar disfuncionamentos por entre as engrenagens desta mesma máquina. Portanto, o trajeto da pesquisa procedeu a um deslocamento radical das análises individualizantes dos processos de trabalho, apostando na ampliação da normatividade vital, ou seja, na expansão da vida em suas diferentes dimensões nas escolas (Canguilhem, 2009).

\section{O Fórum-Cosate como produção do comum: caminhando na contramão da razão neoliberal}

Os dados produzidos no inquérito de saúde percorreram espaços variados, como assembleias convocadas pelo Sindicato dos Trabalhadores em Educação Pública do Espírito Santo (Sindiupes) e seminários de pesquisa, além de reuniões com gerentes da Secretaria de Educação. O convite

8 Poder de agir é um conceito forjado por Yves Clot (2006) para se referir ao poder de criação e de invenção dos sujeitos sobre a atividade. Nesse sentido, podemos aliar este conceito à ideia de que o poder é sempre ação e o agir não tem, necessariamente, uma finalidade (Foucault, 2008). Aqui, tomamos o conceito de poder de agir como um plano das forças que (re)existem à mera execução de tarefas prescritas, indicando a potência de criação e invenção pela atividade dos humanos.

9 Trataremos essa temática no transcorrer deste texto. 
chamava para alguma ação e algum diálogo sobre o tema de interesse comum: as formas de organizar e analisar o trabalho. Com os atores desse cenário, exercitávamos outra maneira de lutar pela saúde e trabalho na Educação do município da Serra, ES.

Foi nessa direção que se engendrou a aposta no Fórum-Cosate: construir dispositivos para acompanhar, avaliar e intervir nas situações de trabalho como política pública da educação. O fórum foi instituído, então, como espaço que prepara e cria condições para a construção de comunidades ampliadas de pesquisa. O fórum constituiu-se como local da partilha de experiências no campo da educação, afirmando-se a laboriosa aposta em espaços de discussão e convivência para a efetiva produção de uma política pública; um ambiente que se fortalece como contraposição à racionalidade neoliberal.

Foi usado o método da Roda ou Paideia (Campos, 2003), visando subsidiar processos dialógicos e encaminhamentos coletivos de forma a legitimar a decisão pela implantação das Cosates nas unidades escolares do município. Um diário de campo fora constituído no formato de Atas, sendo esses dados relativos aos encontros e às pactuações divulgados na rede municipal de ensino. Um Boletim-Cosate também foi criado para ampliar o alcance do processo, restituindo informações aos trabalhadores que não estavam presentes nas reuniões quinzenais ou mensais. A participação dos membros do Fórum-Cosate em mesas, tanto de congressos científicos quanto de congressos de professores e assembleias, ampliava ainda mais o alcance do debate; insistíamos no convite à ampla participação.

Assim, por meio do Fórum-Cosate, novas redes produziram uma comunicação mais articulada entre equipamentos e políticas públicas territoriais. $\mathrm{O}$ fórum não se interessava pela sua formalização como sujeito jurídico, mas pelo seu desenvolvimento como política cognitiva e formativa.

Ao convocar trabalhadores da educação para um fórum, buscamos exercitar a construção de um plano comum, condição para a constituição de uma política efetivamente pública. Lembramos que dialogar e partilhar experiências é desafiador, uma vez que somos insistentemente convocados por forças e modos de vida competitivos, individualizados, solitários, próprios da axiomática capitalista neoliberal. Logo, trabalhar de modo coletivo implica investimentos, exercícios permanentes na produção de coletivo, pois um coletivo não está dado a priori. $\mathrm{O}$ fórum visava, portanto, a uma política pública que não pretendesse falar "sobre" o trabalhador, mas "com" o trabalhador, num exercício de lateralização que colocava lado a lado trabalhadores da rede municipal de educação da Serra e pesquisadores da UFES, indagando práticas verticalizadas - ou mesmo, corporativistas.

O cenário das escolas, marcado por violência, precariedade das condições de trabalho, licenças médicas e alto índice de absentismo exigia a criação de modos para enfrentar as questões de cada caso vivido em suas particularidades. No fórum, buscávamos alimentar confrontos, mas não desqualificações ou antagonismos. A agonística, as confrontações e o dialogismo ditavam o tom das conversas. Cabe destacar que um fórum não existe e não se finda à medida que cada encontro termina, pois a rede constituinte de um fórum nele se alimenta, em uma relação de circularidade: quanto mais viva a rede em suas conexões, mais potente é um fórum em sua experiência de roda.

Assim, o dialogismo no fórum produzia estratégias de fortalecimento dos coletivos de trabalho que se faziam roda, palco de conversas. Conexões eram produzidas, o que possibilitava que os diálogos fossem travados e que as conversas pudessem continuar com outros setores da rede em geral. A experiência de cogestão e de análise era o foco mais importante. Uma atitude problematizadora, que nos colocava insistentemente a questão: o que estamos fazendo como experiência de um fórum enquanto o fazemos? Como estar fórum? Nem fora nem dentro! Estávamos fórum! ${ }^{10}$

Os diferentes espaços coletivos de trabalho nas escolas, como os conselhos de escola, reuniões de pais, conselhos de saúde, de assistência, assembleias das categorias profissionais etc., insistem

10 Slogan que tomava o Fórum Mundial 2000 em Porto Alegre. 
na luta por sua existência, de forma a enfrentar os esvaziamentos dos espaços coletivos de análise do trabalho e afirmar a importância desses espaços no enfrentamento das estratégias neoliberais de isolamento que enfraquecem a força do coletivo. Atravessados por processos de desvitalização, quando imperam diferentes formas de privatização no nosso dia a dia, pergunta-se: como reorientar e dispor as forças na aposta do coletivo? Como reordenar as linhas de composição da realidade de modo a afirmar políticas públicas de educação?

Nesse sentido, a pesquisa foi dando visibilidade a um quadro de adoecimento dos trabalhadores da educação municipal. Além disso, com nossa inserção nesta rede há dez anos,marcados por idas e vindas ao longo deste percurso, foi possível um adensamento com a habitação do território diante das falas que insistentemente apontavam a "falta de tempo" como agente inviabilizador da participação dos trabalhadores nas reuniões do fórum. Machado (2008) nos convida a analisar estas falas e afirma que a "falta de tempo" está longe de ser um dado simplesmente objetivo e inquestionável. Ela não deve ser entendida como causa inequívoca de nossos problemas, pois remete aos efeitos de uma maneira coletivamente reversível de estruturar os tempos e espaços nos cotidianos das escolas. Em outras palavras, para além de ser uma causa/problema indiscutível, a falta de tempo remete a processos de organização neoliberal da ordenação do trabalho em educação. Seguindo a pista que a autora abre, podemos nos reposicionar e lutar pela instauração de outras temporalidades nas atividades do cotidiano educacional.

Baptista e Gatto (2016) nos auxiliam nesta tarefa ao discutir três dimensões distintas e coexistentes do tempo, articulando-as ao cinema e ao trabalho em psicologia escolar. Os autores propõem este debate situando a existência, na Antiguidade clássica, de três conceitos que os gregos dispunham para caracterizar o tempo: khronos, kairós e aión. É a articulação entre estas dimensões coexistentes, e não uma precipitada exclusão de qualquer uma de suas camadas, que nos esforçamos por articular ao longo do trabalho de constituição do fórum como modo de fazer frente à racionalidade neoliberal.

O primeiro aspecto do tempo a ser abordado refere-se à temporalidade linear, cujos acontecimentos podem ser encadeados dentro de uma lógica causal. Seria o nosso velho conhecido khronos: o tempo dos calendários, dos programas e dos cronogramas, das pautas, tempo das frequências e avaliações delimitadas. Esta é, sem dúvida, a racionalidade temporal mais alimentada na formatação da escola-empresa de que vínhamos falando e situando nossa análise.

Baptista e Gatto (2016) apresentam a alegoria do titã khronos, que devora seus filhos, os deuses do Panteão e, assim, os autores põem em jogo a avidez deste tempo que devora a tudo e a todos. "É sobre a ameaça do aniquilamento e do apagamento dos rastros que se opera o tempo cronológico" (Baptista \& Gatto, 2016, p. 2). No interior das escolas e no trabalho de nossa pesquisa, tal dimensão comparece cotidianamente, seja nos planejamentos, seja nas datas prescritas para a entrega de relatórios, nas chamadas relacionadas à frequência dos participantes no fórum e, inclusive, no processo de conjurar o apagamento possível que este devorador traz às suas outras esferas constitutivas (kairós e aión). A racionalidade empresarial investe khronos de incríveis poderes, desconsiderando outras dimensões do tempo também fundantes para a vida. A questão, portanto, não é aniquilar khronos, mas sim evitar que este devorador tome a dianteira e engula outras superfícies temporais igualmente fundamentais para o existir; diga-se, de passagem, como tem ocorrido no contexto da educação contemporaneamente.

O segundo aspecto refere-se à experiência do tempo oportuno que salta sobre nós, o tempo das oportunidades, o "tempo-quando" das ocasióes. Baptista e Gatto (2016) apontam que o deus kairós é descrito na mitologia grega como um ser ágil e veloz, que andava nu e com apenas um cacho de cabelos na testa, o que tornava possível que ele fosse agarrado e segurado por alguns átimos 
de segundo, para, por fim, escapar ligeiro e escorregadio das mãos de quem pôde lhe alcançar por breves instantes.

Walter Kohan (2018) ressalta que kairós qualifica khronos, pois khronos é homogêneo e indiferenciado. Afinal, todo movimento no tempo cronológico é equivalente, de modo que um segundo é igual a qualquer outro e uma hora terá sempre os mesmos sessenta minutos. Assim, khronos é sucessivo, consecutivo e irreversível enquanto kairós, por outro lado, introduz uma qualidade, instaura uma diferença na experiência.

O Fórum-Cosate - nosso foco neste artigo - tinha a função eminente de fazer proliferar os átimos de instante nos quais podemos agarrar o topete de kairós, isto é, de possibilitar uma produção de ocasiões em que estejamos oportunamente posicionados para acolher as diferenças, os tensionamentos, hesitações, titubeios e a indeterminação propícia ao exercício do pensamento na produção de uma coletividade.

Em relação à terceira dimensão temporal, temos ainda aión, o tempo da experiência. Este é muito difícil de ser apreendido em palavras, uma vez que é superfície avessa à espacialidade discursiva. Resta-nos, portanto, tentar uma aproximação por exercício poiético (de criação poética) para lhe tocar as entranhas. Walter Kohan (2018) afirma que "aión é o tempo que não passa, que não sucede, é o tempo que dura" (Kohan, 2018, p. 302). O tempo aiônico é aliado à vibração intensiva, é tempo da qualidade e não da quantidade, tempo da "criança que crianceia" (Kohan, 2018, p. 303).

Na prática e sustentação do fórum, residimos instalados na fronteira entre as inúmeras qualidades incomensuráveis do tempo, suas faces indissociáveis e superfícies de conexão. Em alguns instantes, demos a mão a khronos e caminhamos ao lado dele em linha reta: seguimos obedientes a sua direção. E então nós escolhemos datas para realizar atividades diversas, construímos um calendário de cursos de formação para diretores, professores e outros trabalhadores da educação, organizamos sequências de idas para conhecer e habitar o cotidiano de diferentes escolas, realizamos encontros quinzenais ou mensais do fórum entre os anos de 2012 e 2019. Em outros momentos, estivemos face a face com a dimensão kairós e aión do tempo, por exemplo, quando professores compartilham, no Fórum-Cosate, táticas de resistência aos controles que surgem verticalizados pela Secretaria de Educação municipal, ou quando se dispõem a fazer um cafezinho e levar lanches para o fórum. A potência residia na possibilidade de estarem juntos para partilhar a existência, para "perder tempo", alimentar uma rede de conversações, dispor de um encontro desapressado e para tecer manhãs em um cotidiano marcado por excesso de atividades.

Assim, o caminho construído foi se efetivando como forma de enunciar e colocar em diálogo um coletivo de trabalhadores, uma vez que a aposta é na força dos espaços dialógicos, na ampliação da autonomia, na habitação de outras temporalidades. Buscávamos a construção de um espaço de discussão coletiva das práticas em educação no município de Serra, ES que pudesse se fazer como um dispositivo aberto para ampliar o poder de agir dos trabalhadores da educação. Desse modo, faríamos funcionar modos outros de trabalhar e ser trabalhador e trabalhadora, modos estes que insistem na potência criadora dos humanos. Esta é uma forma de produção de política pública que tem por objetivo constituir um coletivo como fonte de renovação e movimento, indo na contramão da escola-empresa e do educador como empreendedor de si.

Nossa aposta é na produção de políticas públicas como enfrentamento da situação de precariedade do trabalho na rede de ensino em função das políticas de austeridade que esvaziam o ensino público e impõem na rede municipal de ensino da Serra, ES, uma escola-empresa. Habitualmente, quando pensamos em políticas públicas, é quase inevitável conectá-las ao governo, como se este fosse seu único idealizador. Entendemos que políticas públicas não estão, necessariamente, atreladas ao governo, mas, também, surgem como possibilidade de enfrentamento 
ao governo. Foi o caso dos movimentos liderados pelo Sindiupes frente aos desafios que o chamado "pacote de maldades da administração" - nome dado às medidas implementadas pela administração através da Lei municipal no 4.602/17. O "pacote de maldades" produziu retrocessos em algumas conquistas do movimento dos educadores no município, tais como:

- Retirada de seguranças e porteiros das escolas, substituídos por videomonitoramento;

- Redução de liberação sindical: havia previsão de até oito liberações; atualmente, só há previsão de uma;

- Perda do direito de folga no dia do aniversário;

- Não regulamentação da Lei municipal no 4.513/16, que institui Cosates no município de Serra, ES, aprovada na Câmara e sancionada pelo Prefeito;

- Não reposição das perdas salariais - desde 2017, a categoria está sem nenhum tipo de reajuste salarial;

- Dificuldade de atendimento e agendamento de perícia médica da Prefeitura e falta de consenso nos atendimentos entre essa perícia e a do Instituto de Previdência;

- Não implementação da Lei no 11.738, de 16 de julho de 2008, do Piso Nacional do Magistério ${ }^{11}$, especialmente no tocante à carga horária para planejamento.

Muitos movimentos foram feitos para o enfrentamento do "pacote de maldades" produzido pela administração municipal. A realização do fórum foi uma das estratégias de luta, uma vez que a aposta se fazia na criação de espaços cujos dispositivos forjados oportunizassem, com suas ações micropolíticas ${ }^{12}$, ambientes de formação que fossem catalisadores de um ethos de enfrentamento perante tais máquinas de captura.

Nossa aposta no Fórum-Cosate foi construir políticas públicas não alinhadas ao poder do capital e mais comprometidas com a potência e expansão da vida, ou seja: pensar políticas públicas do coletivo para o coletivo. O processo de elaboração do Projeto de Lei, por exemplo, se efetivou nos diálogos do Fórum-Cosate. Constituiu-se em um exercício de lateralização, de corresponsabilização, de atenção ao que se passava no coletivo. Discutir, por exemplo, o que é risco iminente em uma escola e sua possível interferência na paralisação das aulas (com consequências para os estudantes e a comunidade escolar em geral) nos levou a vários encontros e discussões acaloradas. O grupo pôde contar com a experiência dos trabalhadores e trabalhadoras das escolas, dos profissionais da Secretaria de Educação da Serra que participavam do fórum, da promotoria que atuava no campo da educação no município, do Sindicato dos educadores do estado, dos profissionais da Divisão de Medicina e Segurança do Trabalho (DMST) de Serra e, também, do Centro de Referência em Saúde do Trabalhador/ES (Cerest) e Fundação Jorge Duprat e Figueiredo (Fundacentro/ES).

A articulação de todas essas vozes possibilitou a chegada a um comum que não anulasse as diferenças, mas que se constituísse em uma criação, uma composição, uma invenção desse coletivo, sem a pretensão de apresentar uma saída que funcionasse em todas as situações ou se tornasse uma solução-modelo, perfeitamente aplicável a qualquer escola.

Fazemos essa aposta na produção de uma política pública na educação por acreditarmos que ela expressa a força do coletivo, ao contrário das políticas de governo que, em geral, já chegam

11 A Lei n⿳ 11.738/08 institui o piso salarial profissional nacional para os profissionais do magistério público da educação básica. Mais informações podem ser acessadas em Ministério da Educação (2008).

12 Consideramos que toda política é necessariamente macro e micropolítica. Macro e micro não se identificam, aqui, com tamanho, formas grandes e pequenas, nem como relações interpessoais se contrapondo aos planos institucionais protocolares mais verticalizados nas organizações e estabelecimentos. A dimensão micropolítica refere-se aos movimentos que se fazem no curso das nossas ações e que provocam o que está instituído, produzindo movimentos que tentam desestabilizar o que está formalizado. As políticas governamentais, apesar de operarem por macrodecisões, têm uma dimensão de indecidibilidade, pois "a decisão política mergulha necessariamente num mundo de indeterminações, atrações e desejos, que ela deve pressentir ou avaliar de um outro modo" (Deleuze, 1992, p. 102). Logo, uma política que age por meio de julgamentos molares, mas seu acontecer é micropolítico. 
formatadas e sem forte participação social e, por isso, mais frágeis e de menor durabilidade. Estas não valorizam o coletivo e nem denotam processualidade. O comum é produzido ao tecermos a política pública por meio do processo incessante de experimentações - não há respostas a priori.

Aqui, uma distinção se faz importante: chamamos de gerenciamento a função dos secretários, diretores e chefias, e de gestão, realizada por todos os trabalhadores e não apenas pelos gerentes. Essa gestão faz-se atuante no cotidiano das relações impressas pelos trabalhadores em ambiente laboral e está conectada à ação e à tensão em jogo durante o desenvolvimento de suas atividades.

Nosso princípio básico é a ideia de que todos os participantes do fórum são, também, pesquisadores, pessoas que se debruçam sobre a experiência para analisar os modos pelos quais são engendrados os processos de trabalho, para produzir estratégias, produzir força, produzir saúde. Nosso ponto de partida era a ideia de produzir conhecimento, tomando este não como reprodução de verdades, mas como um processo construído coletivamente, que não preexiste à pesquisa. $\mathrm{O}$ aceite dos componentes do fórum era apenas o início da construção do plano comum da pesquisa (Kastrup \& Passos, 2013). Esse plano comum nos remete a uma articulação das diferenças, fazendo com que estas conversem sem que se anulem. É uma construção positiva, pois esse diálogo expõe as tensões, move os sujeitos na pesquisa ${ }^{13}$.

Tal direção metodológica considera que, em pesquisa-intervenção e pesquisas qualitativas participativas, é preciso cultivar uma atenção especial ao processo de convocação dos participantes, que não se restringe ao cumprimento das formalidades de um contrato de participação, isto é, não se restringe à assinatura de um termo de consentimento livre e esclarecido. $O$ processo de contratação efetivou-se por meio de uma duração que viabilizasse contrair um "grupo-sujeito" (Guattari, 2004) no Fórum-Cosate, de forma a criar condições para a realização de uma pesquisa que fosse participativa, com vínculos de confiança, corresponsabilidade e protagonismo distribuído.

\section{Considerações finais}

Podemos dizer que a pesquisa, por meio da estratégia Fórum-Cosate, procurou ter os trabalhadores e trabalhadoras como parceiros, construindo, juntos, um espaço dialógico, repensando os modos de trabalho e, com a força do coletivo, "ampliar o poder de agir" (Clot, 2010) desses trabalhadores e trabalhadoras. Privilegiamos os processos de coanálise do trabalho, processos esses que viabilizam acessar recursos advindos do patrimônio proveniente da atividade dos trabalhadores e trabalhadoras da educação, provocando seu desenvolvimento e transformação.

Não buscamos conhecer para formar, mas transformar para conhecer a realidade da rede educacional da Serra, ES, pois conhecer, no nosso entendimento, não é representar uma realidade, mas se lançar em uma experiência coletiva de criação de si e do mundo.

Percebemos, nos relatos e corpos dos educadores e pesquisadores, como o movimento de produção de comum diz respeito a incluir diferenças, insatisfações, controvérsias e discordâncias. O Fórum-Cosate viabilizou a instituição de comissões de saúde por local de trabalho como dispositivo para potencializar movimentos micropolíticos de resistências à lógica neoliberal que se acirra nas escolas públicas. A partir de uma clínica crítica do trabalho, almejamos inventar novos modos de compartilhamento de experiências e (des)aprendizagens.

13 As comissões de saúde do trabalhador apostam no diálogo permanente sobre os processos de saúde-doença em sua relação com o trabalho, como um modo dos trabalhadores se apropriarem de sua lida e vida no trabalho pela via prioritariamente de intervenções coletivas, no sentido de produzir saúde e sentidos outros ao cotidiano do mundo do trabalho. 
Assim, o fórum buscou estar atento a como temos nos posicionado nessas práticas de governamentalidade e, com esse objetivo, as discussões e os debates com diferentes segmentos da rede municipal de educação foram espaços preciosos para que essas análises ocorressem, pois possibilitaram que os trabalhadores também se percebam pesquisadores e cogestores de seu trabalho, ou seja, o trabalho em educação como invenção de si e de mundos.

\section{Referências}

Baptista, L. A. \& Gatto, V. C. (2016). Quando o cinema invade a escola. RevistAleph, 13(26), 1-13.

Barros, M. E., Muniz, H. P., \& Brito, J. M. (2019). A saúde do trabalhador da educação: a experiência da constituição de Cosates como dispositivo de intervenção numa rede municipal de ensino. Cadernos de Psicologia Social do Trabalho, 22(1), 15-28.

Campos, G. W. (2003). Saúde Paideia. São Paulo: Hucitec.

Canguilhem, G. (2009). O normal e o patológico. Rio de Janeiro: Forense Universitária.

Clot, Y. (2006). A função psicológica do trabalho. Petrópolis, RJ: Vozes.

Clot, Y. (2010). Trabalho e poder de agir. Belo Horizonte: Frabefactum.

Deleuze, G. (1987). Proust e os signos. Rio de Janeiro: Forense.

Deleuze, G. (1992). Post-scriptum sobre as sociedades de controle. In G. Deleuze, Conversações (pp. 219-226). São Paulo: Ed. 34.

Foucault, M. (2008). Segurança, território e população: curso dado no Collège de France (1977-1978). São Paulo: Martins Fontes. Guattari, F. (2004). Psicanálise e transversalidade: ensaios de análise institucional. São Paulo: Ideias \& Letras.

Kastrup, V. \& Passos, E. (2013). Cartografar é traçar um plano comum. Fractal, 25(2), 263-280.

Kohan, W. (2018). A escola como experiência: entrevista com Walter Omar Kohan. Revista Eletrônica de Educação, 12(1), 298-304.

Laval, C. (2004). A escola não é uma empresa: o neoliberalismo em ataque ao ensino público. Londrina: Editora Planta.

Lei estadual no 5.627, de 17 de março de 1997. (1998). Dispõe sobre a criação da Comissão de Saúde do Trabalhador (Cosat) do Serviço Público do Estado do Espírito Santo e o Conselho das Comissões de Saúde do Trabalhador (Concosat). Vitória: Diário Oficial do Estado. Recuperado de http://www3.al.es.gov.br/Arquivo/Documents/ legislacao/html/LEI56271998.html

Lei $n^{-}$11.738, de 16 de julho de 2008. (2008). Regulamenta a alínea "e" do inciso III do caput do art. 60 do Ato das Disposições Constitucionais Transitórias, para instituir o piso salarial profissional nacional para os profissionais do magistério público da educação básica. Brasília, DF: Diário Oficial da União. Recuperado de http:// www.planalto.gov.br/ccivil 03/ ato2007-2010/2008/lei/111738.htm

Lei municipal no 4.513, de 05 de maio de 2016. (2016). Cria a comissão de saúde do trabalhador da educação (Cosate) do servidor público do município de Serra, ES e o conselho das comissões de saúde do trabalhado da educação (Concosate). Serra, ES: Prefeitura de Serra. Recuperado de http://prefeiturasempapel.serra.es.gov.br/Arquivo/ Documents/legislacao/html/L45132016.html

Lei municipal no 4.602, de 23 de janeiro de 2017. (2017). Dispõe sobre medidas de contenção de despesas, alteração de dispositivos e dá outras providências. Serra, ES: Câmara Municipal. Recuperado de http://legis.serra.es.gov.br/ normas/images/leis/html/L46022017.html

Luciano, L., Barros, M. E. B. \& Raizem, M. H. (2016). Configurações das relações entre trabalho e saúde de professores do ensino fundamental. In M. E. B. Barros, J. M. Cesar \& F. H. Silva (Orgs.) Saúde e trabalho em educação: desafios do pesquisar (pp. 201-223). Vitória: Edufes.

Machado, A. M. (2008). A produção de desigualdade nas práticas de orientação. Recuperado de http://www2.fe.usp.br/ $\sim$ cpedh/Desigualdade\%20e\%20Educ\%20Adriana\%20Marc.pdf

Oddone, I., Marri, G. \& Gloria, S. (1986). Ambiente de Trabalho: a luta dos trabalhadores por saúde. São Paulo: Hucitec. 
Prefeitura Municipal de Serra (2020a). A educação na Serra: quantidade de unidades escolares da rede municipal de ensino. Serra, ES, 2020a. Recuperado de http://www.serra.es.gov.br/site/pagina/a-educacao-na-serra

Prefeitura Municipal de Serra (2020b). Alunos da Serra vão ter aulas de honestidade, respeito e até meditação. Serra, ES, 2020b. Recuperado de http://www.serra.es.gov.br/site/publicacao/alunos-da-serra-vao-ter-aulas-de-honestidaderespeito-e-ate-meditacao

\section{Endereços para correspondência}

betebarros@uol.com.br

crisbremenk@gmail.com
Recebido em: 29/09/2019

Revisado em: 13/06/2020

Aprovado em: 08/07/2020 